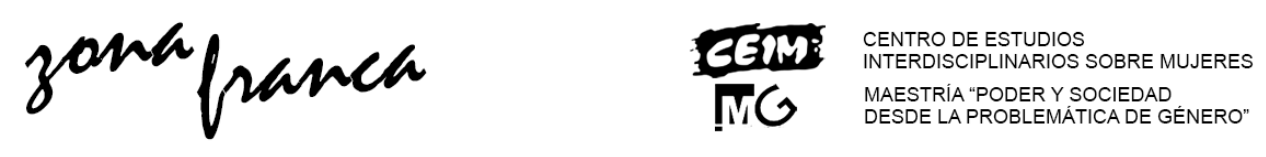

\title{
Las prioridades ocultas
}

\begin{abstract}
Valérie Lefebvre-Faucher
En estas condiciones de desconexión, es evidente que el fenómeno de la vida no puede mantenerse, es NORMAL, ¿entiendes? - (Areski a) Brigitte Fontaine, en la canción "C'est normal".
\end{abstract}

En 1990 le preguntábamos a Suzanne Jacob qué pensaba sobre el 50ํㅜ aniversario del derecho a voto de las quebequenses, y ella se obstinaba en responder: "la pregunta es qué comemos". En pocas palabras, la escritora quería recordarnos que el derecho de voto (o al menos el voto) de las mujeres resulta un fracaso si no nos asegura poder alimentar a la gente. Ahora podríamos generalizar esta respuesta y plantearnos: este sistema, esta transformación del sistema, ¿acaso permite alimentar a la gente? Si la respuesta es no, entonces no sirve.

Es esta desconfianza, este desvío en la discusión, este rechazo frente a lo que se nos ha presentado como normal, lo que constituye para mí el movimiento central del ecofeminismo: la reivindicación, ya conocida e irrefutable, de una inversión de las prioridades o, lo que es lo mismo, el rechazo a dejar de lado la humanidad y la vida en su conjunto.

*Titulo original del artículo: "Les priorités cachées". En Marie-Anne Casselot y Valérie LefebvreFaucher (compiladoras) (2017), Faire partie du monde. Réflexions écoféministes (139-157), Les éditions du remue-ménage, Québec. Traducción: Soledad Rojas Novoa

Revista Zona Franca- Centro de estudios interdisciplinario sobre las mujeres (CEIM)- Maestría poder y sociedad desde la problemática de género (MG), Rosario, Argentina. ISSN, 2545-6504 http://zonafranca.unr.edu.ar/index.php/ZonaFranca| Numero 26 (2018). 
Podemos confrontar este rechazo a todo tipo de situaciones, incluso si su sentido político no es evidente a primera vista. Identifico actitudes y reflexiones ecofeministas en muchas personas alrededor mío, y me gustaría comprender este hecho como una radicalización del feminismo, una politización de la ecología, que complejiza nuestras luchas y les exige mayor coherencia. Me gustaría que no fuese posible seguir ignorando tal radicalización. Me gustaría decir que feministas y ecologistas cometen un error, al menos estratégico, si no fundamental, al no avanzar en conjunto.

Pero también sé que esta demanda es exigente. Ella requiere del encuentro entre análisis y objetivos que no parecen ir siempre de la mano. Lo que pido es tolerar la incomodidad que suscita el carácter complejo de las luchas, escuchar a las insatisfechas, a las que no se conforman con la normalidad, las que parecen insensatas y otras veces caminar pisando huevos. En las páginas que siguen les propongo seguirme en mis propias contorsiones. He aquí lo que veo mientras hago equilibrio entre múltiples luchas, múltiples hilos que no van en la misma dirección pero a partir de los cuales tengo la convicción de que es posible tramar un tejido sólido. Me concentraré entonces en algunos nudos que me parecen particularmente interesantes y complejos. Aquí no encontrarán un programa de partido ni demostraciones científicas, sino, más bien, una serie de críticas e inversiones, una mirada feminista y una inquietud ecologista.

Las reivindicaciones ecofeministas emergen de una desconfianza, de una postura crítica, pero también de cierta relación a la urgencia. Ellas comienzan por 
gestos de cuidado que no tienen nada que ver con un heroísmo militante; más que a demoler, nos incitan a recoger lo que se cae a pedazos; hacen aparecer proyectos invisibles y rechazar el orden de las cosas tal como se presenta. ¡No nos hablen de historia ni de beneficios si la vida no está asegurada!

Tampoco nos pidan que jerarquicemos las vidas. ${ }^{1}$ Esta segunda dimensión de la desconfianza ecofeminista no es menor, incluso si se trata de aquella que, al calor de la lucha ecologista, tendemos a dejar de lado. Frente a la crisis en la cual estamos inmersos/as, frente a la inminencia de la catástrofe, podría resultar tentador no discutir demasiado sobre los procedimientos. Salgamos del capitalismo, dicen algunos, cambiemos nuestro estilo de vida o invirtamos en el progreso tecnológico, y puede ser que la vida sobre la Tierra tenga posibilidades de continuar... ¿Qué es eso de andar pensando en el interés de su grupo, mientras nosotros pensamos en la sobrevivencia general?, se les reclama a las mujeres. Ahora bien, hablar en este preciso momento de igualdad, respeto y justicia se vuelve urgente justamente porque estamos discutiendo la sobrevivencia -nos preguntamos cómo sobrevivir y también quién podrá sobrevivir. ¿Una elite en un búnker o la humanidad entera? ¿Los superdepredadores enfermos o un

${ }^{1}$ Lógicamente, aquí se puede leer "todos los seres vivos". De hecho, me alegro de estar del lado de Élise Desauliniers, que conoce mejor que yo el aspecto anti-especista de las luchas. Por mi parte, me parece importante poner atención específicamente en la jerarquía entre las vidas humanas, pues incluso ellas están lejos de ser consideradas como iguales (tal como nos lo recuerda con elocuencia el movimiento Black Lives Matters, por ejemplo). Cabe considerar que entre las feministas existe un movimiento al menos doble, que tiende hacia un mundo ideal, liberado de toda dominación, pero que busca defender a las mujeres como grupo por razones estratégicas. Personalmente, estoy cerca de la historia de aquellas que combatieron con fuerza por no ser consideradas como animales. Afirmar que todas las vidas valen plantea un gran desafío para las mujeres, en la medida que el valor de sus vidas no está garantizado. Es urgente admitir la interdependencia de todas las vidas y repensar un feminismo capaz de descentrar la humanidad.

Revista Zona Franca- Centro de estudios interdisciplinario sobre las mujeres (CEIM)- Maestría poder y sociedad desde la problemática de género (MG), Rosario, Argentina. ISSN, 2545-6504 http://zonafranca.unr.edu.ar/index.php/ZonaFranca| Numero 26 (2018). 
conjunto complejo y diversificado de formas de vida interrelacionadas? La crisis ecológica hace desaparecer las especies y produce víctimas cada vez más numerosas, primero en las poblaciones más pobres y menos libres... El ecofeminismo me dice la vida primero, sí, toda la vida. Dan ganas de rechazar cualquier pretendida racionalidad que se ubique como superior al respeto de la vida. Para afrontar las catástrofes se requieren soluciones políticas y opciones solidarias. No aceptamos el rechazo de los/as refugiados/as climáticos, la creación de villas privadas, ni ninguna de esas reorganizaciones reticentes a la vida en común, estas burbujas "sanas" reservadas para los más fuertes. Ninguna solución vendrá de aquello que nos separa de las otras especies, enfermas como nosotras de contaminación, ni de la pretendida humanidad global, cada vez más hambrienta y amenazada.

\section{Crisis de la reproducción}

Esta disputa de las prioridades, este desplazamiento ecofeminista de la atención, permite abordar las crisis en las cuales el mundo está sumergido a partir de un ángulo a menudo ignorado: el de la reproducción. Esta palabra, tan desagradable muchas veces, encuentra un lado práctico para los economistas y los sociólogos; su sentido es rico y se deja comprender por los militantes de izquierda, a quienes es bueno recordarles de vez en cuando que las mujeres también son productivas. Asimismo, puede ser que permita a algunos ecologistas apreciar la vida como un fenómeno libre y autónomo, y esforzarse por su reproductividad más que por su control. Esto a lo que nos enfrentamos es descrito 
actualmente por muchas feministas como una gigantesca crisis de la reproducción (algo que Naomi Klein llamaría crisis de la fertilidad). ${ }^{2}$

La reorganización capitalista del trabajo que conocimos en los años 1980 y 1990 (reaganismo, thatcherismo, neoliberalismo, mundialización), ha resultado en un ataque directo a los fondos públicos consagrados a la reproducción (salud, educación, condiciones de trabajo, etc.), lo que ha producido una crisis muy importante de la reproducción.

Quien plantea este diagnóstico es Silvia Federici (en Toupin, 2014) ${ }^{3}$. A ella habría que recurrir para comprender las estrategias de control de los medios de reproducción, los recursos y el cuerpo de las mujeres por parte de nuestras elites, así como sus devastadores efectos.

Por su parte, Mariarosa Dalla Costa (en Toupin, 2014) nos señala:

Los alimentos que tradicionalmente eran una fuente de alegría, de a poco dieron origen a miedos y sospechas. Si abastecer de comida ha constituido una de las tareas fundamentales del trabajo de reproducción de las mujeres, dicha tarea, como por azar, enfrenta ahora numerosos problemas: no solamente que los alimentos devienen escasos, tanto en el Sur como en el Norte, si no que además devienen insalubres. En consecuencia, en muchas regiones, las mujeres toman la cabeza de los movimientos para preservar la vida y los alimentos.

${ }^{2}$ A propósito de su propia experiencia de infertilidad, en Tout peut changer, Klein $(2015$, p. 478) sostiene: "Comprendí mi pertenencia a esta vasta familia terrestre donde una y mil especies intentan reproducirse contra viento y marea".

${ }^{3} \mathrm{~N}$. de T. Esta y la siguiente cita son extractos de entrevistas hechas por Louise Toupin (2014). La autora no consigna número de página.

Revista Zona Franca- Centro de estudios interdisciplinario sobre las mujeres (CEIM)- Maestría poder y sociedad desde la problemática de género (MG), Rosario, Argentina. ISSN, 2545-6504 http://zonafranca.unr.edu.ar/index.php/ZonaFrancal Numero 26 (2018). 
El interés por la categoría general de reproducción, inmediatamente ubica en primer plano las acciones y preocupaciones prioritarias de la humanidad que a menudo debemos postergar. Cuando digo reproducción, no hablo sólo de una teoría económica, sino sobre todo de los gestos e intenciones que permiten sobrevivir. En horas en que numerosas especies (entre ellas la nuestra) son amenazadas de extinción a mediano plazo, parece razonable hablar de crisis de la supervivencia. $Y$ no es un azar si esta crisis se produce justo en el momento en que se nos arrebatan los medios para mantener y cuidar la vida. Entonces se trata de una crisis de la reproducción pues, además de nuestro propio miedo a la extinción, las batallas que se juegan en este momento atañen a los recursos, el agua, el acceso a la tierra y la alimentación saludable, así como a la superación de la biología en manos de los sistemas: una especulación financiera, una tecnología, que se autonomizan en relación con los seres vivos. Si corremos el riesgo de perder los medios para reproducirnos ¿por qué los movimientos, las ideas, las luchas que conciernen a la alimentación, la salud, la educación, el nacimiento, la familia, son tan fácilmente descuidadas? Se trata de luchas que perdemos porque conciernen a los débiles. Son luchas sin gloria.

Son también luchas que atemorizan. De hecho, ¿qué hay más amenazante para el orden patriarcal que una huelga de la reproducción? Puesto que el miedo a la desaparición de la vida aumenta, se intensifica también el enfrentamiento entre aquellos que buscan mantener el poder de las elites, el control del Estado y de la industria sobre los cuerpos, y aquellos, o sobre todo aquellas, que se consagran a cuidar a los seres vivos. Es necesario comprender que el deseo de controlar la 
contracepción o la agricultura, por ejemplo, puede provenir, de un lado o del otro, de una misma inquietud -es por eso que a menudo es difícil discernir quiénes son los/as aliados/as en este combate, que tiene múltiples frentes. Ahora bien, las mujeres desconfiarán con razón de cualquier proyecto que las relacione con campañas de repoblación o les exija esterilizarse. El control estatal, jurídico, religioso, incluso el control médico de la reproducción, casi siempre ha significado para ellas, en lo concreto, una desposesión y una deshumanización. Pero las mujeres no son recursos. Ellas siempre han sido agentes de la reproducción. Y desde el momento en que los escritores y los políticos hablan de ellas como de tierras cultivables, su revuelta se vuelve más amenazante.

Sostengo que en la lucha por la autonomía y el acceso a los medios de reproducción hay una clave esencial para la ecología contemporánea.

Este interés por la reproducción suscita toda clase de corrientes de ideas. Yo me alimento de las propuestas por las feministas marxistas, quienes han revelado la industria social, así como han defendido el salario para el trabajo doméstico por cierto, ideas que sostienen los pilares de Remue-ménage. ${ }^{4}$ La reproducción a la que ellas se refieren comprende el conjunto del trabajo invisible y gratuito -la comida, la escucha, el cuidado, la educación, el aseo-, y todo aquello que sirve para producir (también es importante para ellas que quede claro que la reproducción es producción) y para mantener a los trabajadores. No quisiera

\footnotetext{
${ }^{4}$ N. de T. Remue-ménage es la editorial que publica el libro en el cual está compilado este artículo. Se trata de una casa de ediciones canadiense, fundada en 1976 como la primera editorial feminista francófona en América. La autora de este artículo fue la editora de Remue-ménage hasta 2018. 
mezclar del todo esta idea de la reproducción con la de care, la cual viene a ser una suerte de heredera, sobre todo para evitar banalizar el potencial revolucionario de las reivindicaciones precedentes. Creo también necesario tener presente al menos una definición más, que circunscriba la reproducción como una actividad precisa, que incorpora el proceso que va de la ovulación al nacimiento. Si no todas las mujeres han pasado por esta experiencia específica de la reproducción, de todas formas su explotación y menosprecio en general están íntimamente ligados al peso de esta tarea de reproducir la especie. Hacer el ejercicio de considerar el nacimiento entre nuestras necesidades fundamentales nos obliga a pensar de otra manera. La actividad que nos interesa no es más la producción-consumo, sino el mantenimiento, en un tiempo cíclico, de la vida. Cuando hablo de reproducción pienso en todas esas definiciones al mismo tiempo. Comer, cuidar y dar a luz. Estas actividades que quedan en la penumbra, que las sociedades modernas han querido ver realizadas por las mujeres (de forma discreta, gratuita y por amor), continúan siendo desacreditadas. El salario, la idea misma de cálculo del tiempo de trabajo, no conviene, en efecto, al reconocimiento de la contribución a la vida. Por eso es que tengo tantos deseos de que existan proyectos colectivos que pongan en valor y celebren estas actividades.

En lugar de estar siempre intentado reubicar a los "otros", las mujeres (y primero las trabajadoras pobres) en su lugar de reproductoras, la sociedad podría hacer de la vida su proyecto prioritario. Porque si esta sociedad no reconoce, o nunca se vuelve capaz de valorar todo lo que supone la reproducción, nunca alcanzaremos la gloria. Lo que nos hace falta es ver el poder que ya tenemos en 
nosotras al ocuparnos de las tareas invisibles. Antes del salario, e incluso antes del respeto, las personas que se consagran a la reproducción ocupan un lugar, un espacio, y ya tienen actividades de poder. ¿Qué más potente que este saber, saber sanar, saber dar a luz (o no...)? Una parte importante de nuestra historia y de nuestra civilización tiende a disminuir la importancia simbólica de la reproducción, mientras busca controlarla. Yo me pregunto lo que pasaría si las mujeres, las mujeres exhaustas de todo el mundo, lograran encontrar en esa carga en común un poder que no las aplasta, sino que ellas dominan.

\section{La maternidad y el sentido}

En La dialectique de la reproduction, Mary O'Brien (1981) dice: “Si me preguntan dónde situar el punto de partida de la teoría feminista, yo contesto: al interior de los procesos de reproducción humana".Muchas feministas han intentado dar a la maternidad un sentido político fundamental y no puedo dejar de abordar aquí esta cuestión tan cautivante. Jamás he pensado que las mujeres están naturalmente predispuestas a algún tipo de sentimiento maternal, cualquiera que éste sea, teórico o universal. Al mismo tiempo, desconfío de todo aquello que glorifica el rol maternal a riesgo de confinar a la mujer en tal rol. Dicho esto, me rebelo también ante los discursos que banalizan la maternidad, que hacen de ella un asunto privado, una elección de consumo, una decisión individual, más o menos irresponsable, incluso egoísta.

El nacimiento es, por el contrario, un tema tan público que las mujeres embarazadas no se pertenecen más a sí mismas. Llueven sobre ellas órdenes 
contradictorias, repoblar, decrecer, vivir sanamente, apretarse el cinturón, y así, una avalancha de discursos, más o menos bien intencionados, que se entrecruzan sobre sus vientres, sin que su palabra sea necesariamente reconocida como válida. La reflexión sobre el sentido político y espiritual de la experiencia de dar a luz continúa marginalizada, como un campo teórico secundario y poco serio, mientras que la reproducción (en el sentido estricto) es un prisma a través del cual podemos pensar el funcionamiento de nuestras sociedades y nuestra relación al mundo. El poderoso gesto de traer una persona al mundo, y a la sociedad, permanece como una especie de cavidad en la filosofía y el pensamiento político. Es aquello que se supone que se hace por sí sólo, naturalmente, sin pensar, por amor, a escondidas. Un hecho fundamental, pero casi vergonzoso. Todavía hoy se le trata como un fenómeno biológico equívoco y que ha de ser puesto en manos de las autoridades. Afortunadamente, las madres y las parteras han empezado a pensarlo y celebrarlo de otro modo.

Sin duda existen muchas maneras de acceder a la revelación de nuestro lugar en la especie o en la historia. El embarazo, como posibilidad de devenir realmente doble, de no ser más completamente dueña de sí misma, es por excelencia uno de esos momentos. Al no pertenecerse más, una persona embarazada puede vivir un sentimiento más o menos violento de alteridad, de despersonalización, de humillación; puede también sentir un exceso en su cuerpo, y la solidaridad, la integración en el grupo. Para aquellas que han sido educadas en el individualismo y la libertad individual, es necesariamente una conmoción. Y una transformación. 
Muchos/as de nuestros/as contemporáneos/as viven esta transformación participando de grandes proyectos colectivos; la espiritualidad, por ejemplo, en un despertar ecologista, que lleva a la gente a sentirse en unión con la tierra, a ponerse al servicio de una causa, arriesgando a veces su vida para salvar los ecosistemas. Misoginia aparte, ¿por qué sería más difícil reconocer este movimiento, esta entrega y generosidad, en la parentalidad así como en la reproducción? En cuanto al sentimiento de unión con la humanidad y con la naturaleza, creo que podemos tener acceso a él de múltiples maneras (por momentos nos vienen como revelaciones, sobre todo cuando nos interesamos por la historia, el arte o la literatura), pero que se vuelve particularmente presente cuando tejemos lazos familiares, y de manera manifiesta, por cierto, al momento en que esos lazos nos atraviesan físicamente.

Me ha sucedido encontrar mujeres a las que mi feminismo ofende, pues pone en cuestión el mito femenino de la conexión con la naturaleza y de la responsabilidad del ciudado. Pienso en Daniela, a quien conocí en Sainte-Rosedu-Nord, para el festival ecologista Virage. Con mucho dolor, ella renunciaba a su deseo de hijo/a porque le preocupaba seguir destruyendo el mundo o hacerle daño a otra persona. Ella trasladaba su sentimiento maternal al mundo entero y se aferraba rotundamente a eso que nosotras llamamos una responsabilidad "maternal". Mi deseo de evocar el maternaje universal, o el sentimiento de responsabilidad colectiva, la desposeía de algo. Nunca estaremos de acuerdo, ella y yo, pues para mi es esencial, para la igualdad, que esta responsabilidad no recaiga únicamente en las mujeres. Sin embargo, también espero hacer honor a lo 
que ella quería defender, es decir lo sagrado, el lazo sagrado entre las generaciones, incluso si tal lazo no tendría por qué ser esencialmente femenino. Una responsabilidad que de hecho no necesitamos ser madres para aprobarla. Si yo me opongo a que esta responsabilidad incumba primero a las mujeres como grupo, no es porque la rechace en lo absoluto. Al contrario. Se trata de restituir esta carga prioritaria y colectiva. La infancia no es un asunto de las mujeres; la alimentación no es una cuestión privada; el nacimiento no es realmente una decisión individual. Es justamente aislando a las mujeres que les quitamos el gran poder que viene junto a estas enormes responsabilidades.

El embarazo es sobre todo la experiencia (y la metáfora) de ese poder, de esa responsabilidad que recae sobre aquellas que vinieron antes en la historia. Devenir, realmente, físicamente, esta barrera entre la vida alveolar, la vida frágil del cigoto, y la hostilidad del mundo, nos enseña algo sobre el "sentido de la familia", tan apreciado por los nostálgicos del patriarcado. El sentido de la familia tiene menos que ver con la protección de una estructura social que encierra a unos en beneficio de otros, que con la consciencia de lo que progresa y muere, y nuestro compromiso en la lucha de los más débiles. Por el contrario de lo que a menudo se les reprocha, las feministas desde siempre han hablado de familia, de niños/as, de cuidados y responsabilidades. Ellas han propuesto hacer estallar el orden familiar, hacerlo más justo, expandiendo la responsabilidad de cuidado a todos, y han recibido como respuesta que "se pasan de la raya". Los hombres, los que toman decisiones en los momentos de crisis, continúan mediando esta responsabilidad en relación con los símbolos y el dinero, pero ¿qué ganarían, qué 
ganaríamos todos, interesándonos por lo que hacen las madres y las madrinas, apoyándolas y aceptando parecernos a ellas?

\section{Los/as niños/as contaminantes}

¿Es irresponsable traer niños/as al mundo en las condiciones actuales? Esta tesis me parece bastante en boga (la derecha se preocupa por la sobrepoblación; los verdes esperan reducir su huella ecológica; las feministas se sublevan frente a los mandatos de la maternidad); ella autoriza incluso a expresar un cierto desprecio por los/as niños/as. Esta postura a veces se acompaña de una grosera discriminación por la gente mayor, una desconsideración por los más débiles (y una molesta inclinación hacia el eugenismo), que, en mi opinión, forma parte de las actitudes humanas más problemáticas. El llamado a tener menos hijos/as, sin gran sorpresa, parece a menudo dirigido hacia los otros, en especial las mujeres pobres, enfermas o racializadas. ${ }^{5}$ Además se integra perfectamente en una cultura que trata a los/as niños/as como gastos y molestias a encerrar, mientras se espera su edad útil, en escuelas en ruinas que les enseñan a volverse consumidores.

Puede resultar tentador proponerles a quienes defienden tal rechazo de la especie humana, comenzar por dar el ejemplo. ¡Y esto no es ni siquiera un chiste! El rechazo individual a contribuir a la reproducción humana se ha transformado en un movimiento ecologista importante. También ocurre que las reflexiones

\footnotetext{
${ }^{5}$ El verano antes de publicar, no en 1950 sino en 2017, las mujeres originarias de Cánada denunciaban su esterilización forzada. Nota de Judith Bartlett y Yvonne Boyer -"Stérilisation des autochtones: des chercheuses réclament une enquête nationale"- disponible en: https://ici.radiocanada.ca/nouvelle/1048119/sterilisation-femmes-autochtones-enquete-nationale-saskatoon-santediscrimination-ligature-trompes

Revista Zona Franca- Centro de estudios interdisciplinario sobre las mujeres (CEIM)- Maestría poder y sociedad desde la problemática de género (MG), Rosario, Argentina. ISSN, 2545-6504 http://zonafranca.unr.edu.ar/index.php/ZonaFranca| Numero 26 (2018). 
ecologistas desalientan la esperanza en la humanidad al punto de desear su extinción. Con más frecuencia aún, la angustia ecológica puede acompañarse de una desesperanza opaca. Yo ya estoy asombrada de la rabia y el desprecio con que llegan a expresarse en ciertas redes militantes a propósito de la reproducción. ¿Cómo podríamos interesarnos por el care y militar por "privilegiar la vida antes que el dinero", si ni siquiera somos capaces de hacer una reflexión feminista colectiva sobre lo que verdaderamente significa reproducir? Yo me ubico más bien entre aquellas que, a pesar de todo, creen en las soluciones políticas y sociales, y por tanto, en la posibilidad de una educación verde y revolucionaria. Pero no estoy blindada contra el pánico; no puedo negar que los humanos son un peso difícil de sostener para sus ecosistemas y que su acción los ha transformado de una manera irremediable y catastrófica. Aquellos que hacen las guerras, los sweat shops $^{6}$ para fabricar trastos envenenados e irrecuperables, son nuestros semejantes. Nosotros mismos somos esos horrores. Por eso cada humano de más abona al riesgo.

Traer niños/as al mundo no es siempre una elección, pero es siempre un acto con consecuencias serias. Si bien puede no ser suficiente para reducir la incertidumbre ante el fin del mundo, al menos supone la posibilidad de elegir la esperanza, de situarse en un ciclo de creación más que de destrucción. Elegir o aceptar el ejercicio de la parentalidad es comprometerse a no renunciar, y eso es político. (Si ser padre/madre no es siempre una elección, tomar esta decisión

\footnotetext{
${ }^{6} \mathrm{~N}$. de T. La autora ocupa el término en inglés para nombrar lo que en francés también se ha llamado "talleres de explotación" o "talleres de miseria".

Revista Zona Franca- Centro de estudios interdisciplinario sobre las mujeres (CEIM)- Maestría poder y sociedad desde la problemática de género (MG), Rosario, Argentina. ISSN, 2545-6504 http://zonafranca.unr.edu.ar/index.php/ZonaFranca| Numero 26 (2018). 
tampoco es siempre suficiente para un nacimiento). Pero cada persona que se encuentra en esta posición se ve dirigida hacia las generaciones siguientes, comprometida con ellas.

Esta dimensión política en la posición parental es con frecuencia ignorada, incluso ridiculizada. Tomo por ejemplo el miedo, alimentado por algunos machos, de la "atiación" del mundo. La "atiazada", esa mujer un poco molesta y aguafiestas, que para lo único que sirve es para sermonear y matar las pasiones, es un repelente en muchas culturas y en numerosas épocas. Yo personalmente amo a aquellas que pasan por arpías insignificantes. ¡Viva la atiación del mundo! En esta sociedad que durante tanto tiempo nos ha hecho consumir como si no hubiese un mañana, sentirse responsable de la generación que viene, y por tanto responsable del mundo, ciertamente no es una postura fácil. Ahora bien, es tiempo de crecer. ¿Y si todos y todas devenimos un poco más tías, es decir, si nos investimos cada vez más con la educación, el cuidado, el avenir? ¿Qué pasaría?

Quienes se declaran antifeministas reprochan bastante a las feministas el haber rechazado, incluso destruido, la familia. Sin embargo, esto revela una gran ignorancia de los escritos y las luchas feministas, pues entre las obras de estas mujeres existe una vasta y sólida tradición de reflexiones sobre la vida, el nacimiento, la infancia, la cooperación y el cuidado de los demás. El punto es que

${ }^{7}$ N. de T. La autora aquí utiliza el término "matantisation". Se refiere, en jerga quebequense, a la "matante", de forma peyorativa, una mujer que se considera obsoleta o pasada de moda, demasiado minuciosa o "maniática". En francés la palabra emerge al unir la palabra "tía" [tante] al pronombre posesivo "mi" [ma]. En Argentina, entre los jóvenes se puede utilizar en un sentido similar con las expresiones que aquí utilizo: atiación o atiazada [todas las referencias a esta expresión están en cursivas en el texto].

Revista Zona Franca- Centro de estudios interdisciplinario sobre las mujeres (CEIM)- Maestría poder y sociedad desde la problemática de género (MG), Rosario, Argentina. ISSN, 2545-6504 http://zonafranca.unr.edu.ar/index.php/ZonaFranca| Numero 26 (2018). 
ellas han defendido una visión amplia de la familia, en la cual la responsabilidad con las generaciones futuras no descansa exclusivamente en los hombros de las madres. Estas ideas han sido muy bien explicadas por bell hooks (2017), quien también parece apreciar la posición de tía.

La educación de los niños es una responsabilidad que puede ser compartida con otras personas, sobre todo con gente que no vive con niños. En esta sociedad, esta forma de parentalidad es revolucionaria pues se ubica en oposición a la idea de que los padres o madres, y en particular las madres, deberían ser las únicas personas a cargo de cuidar a los niños. (...) Este tipo de responsabilidad compartida en el cuidado de los niños puede existir en el contexto de pequeñas comunidades donde la gente se tiene confianza. Esto no puede producirse en contextos en que los padres/madres consideran a los niños como su "propiedad" o su "bien".

Ocuparse de los/as niños/as no es solamente una tarea ingrata que las madres realizan por culpa y que todas buscan pasarle a alguien más, como una papa caliente. Es además, francamente, lo que mejor podríamos hacer, todos y todas. Cuando proponemos que más gente se comprometa con el cuidado de las próximas generaciones, hablamos justamente de cuidado, de educación y de todas las actividades invisibles e imposibles de cuantificar. No se trata de dinero. Esto me parece esencial de comprender: somos prácticamente incapaces de tener consideración por aquello que no se paga, que no se vende. Incluso si los/as niños/as, sobre todo aquellos/as que tienen el poco decoro nacer en familias de clases medias o acomodadas, pasan los primeros años de su vida cubiertos/as de regalos. ¿Cómo es que en nuestras sociedades resulta tan automático, tan inevitable, entregar amor y apoyo a un/a niño/a a través de un juguete, un pastel o 
un regalo? Como padres y madres, consagramos una energía desbordada a un trabajo agotador y menospreciado, a contracorriente de nuestras familias, una batalla que solamente los más tenaces o los parias no pierden del todo, que consiste en detener el caudal de objetos y mimos que sepultan a los/as niños/as. En cada casa, sobre cada niño/a, invade un caudal de golosinas imposible de tragar y del cual una parte importante termina en la basura, un océano de plástico que triplica la huella ecológica de cada individuo. Es esta colonización del amor por el dinero lo que hace que nuestros/as niños/as contaminen tanto y cuesten tanto al planeta. ¿Cuándo fue que nuestra relación al dinero reemplazó nuestras aptitudes de tías?

Mostrarles cómo se pueden hacer las cosas, escuchar sus interminables historias, dejar que jueguen en lugares donde no se puede -entre nuestros pies-, tener una presencia regular, esperar mientras avanzan a su paso lento, decirles que nuestra puerta está abierta, organizar espacios comunes para que sean bienvenidos/as. Hacer que la educación y la preservación del medioambiente sean los más grandes de todos nuestros bellos proyectos. Para atiarse, no es suficiente hacer un cheque. Sí, ponemos presión sobre las mujeres para que ellas tengan niños/as, pero esta presión es el peso de la norma. Lo que se valora en nuestra sociedad es conformarse lo más posible con la ficción, tener un salario, tener un auto, una pareja hetero, una hipoteca y dos hijos/as. Pero no son los/as hijos/as como seres humanos, si no como nivel de vida. Mientras el peso de la parentalidad permanece en la intimidad, escondido. 
Los/as niños/as no necesitan que proyectemos en ellos/as nuestros deseos capitalistas, insaciables e insatisfechos, ni tampoco nuestros miedos ante un futuro trágico. Ellos/as están junto a nosotros en este barco. Puede ser tiempo de que los/as consideremos como marineros y no como mercancías de sobra en la bodega. "Los verdaderos revolucionarios [nos dice Bersianik, 1976, p. 305] son los/as niños/as si los dejamos actuar, porque, al no ver el mundo con los mismos ojos, lo cambian regularmente, sin demasiados reparos, esto forma parte de sus juegos".

\section{Amor y poder}

El amor no es un salario, es un regalo (y si no, es la excusa para un robo...).

Hay algo de vertiginoso en hablar de amor en un contexto feminista. Veo trampas por todos lados y bien articuladas. En la educación de las niñas, el amor es su saber, su carga, su valor, su prisión, todo al mismo tiempo. Es por amor que se espera que las mujeres se ofrezcan; es "por amor" que se las mata. El mandato de amar, de amar a los hombres, aún recae sobre las mujeres, incluso sobre las feministas más radicales, que deben continuamente reafirmar que aman a los hombres. Si claro, los amamos.

Pero ¿qué es el amor? ¡He ahí una pregunta interesante!

Una vida no es suficiente para responder, pero me gustaría al menos comenzar por mirar por el retrovisor al amor del que venimos, y el amor que queremos encontrar. Contamos con la herencia del amor romántico, el de la 
poesía, que tanto nos fascina pues se eleva más allá de las personas y las contingencias, aquel que nos permite amarnos a nosotras mismas a través de alguien más. Esta forma de amor conlleva un aura de belleza absoluta, que perdona las violencias y oculta toda responsabilidad. Las mujeres y la Naturaleza, estos dos objetos del amor romántico por excelencia, desaparecen en este desvío de la mirada. Cuando hablo de amor al mundo, desde la posición de una ecologista ingenua, tengo miedo de este tipo de fascinación, de su separación, donde el mundo no es más que el objeto de nuestra pasión teórica. Las feministas han desenmascarado con tanta precisión la fachada romántica que deberíamos equiparnos de sus herramientas para detectarla cuando se trata del amor al mundo. Amar al mundo no implica mostrarse extasiado frente a él.

En Quebec también recibimos la herencia del amor cristiano, que afirma que el mundo nos ama como un padre compasivo frente a la crueldad de su hijo. Este es el tipo de amor que se acomoda a la jerarquía y la injusticia. Es un amor servil, un amor divino. Amamos a nuestro Creador en humildad y total entrega. En cambio, Él vierte sobre nosotros el amor benevolente de quien es superior y responsable. Nos confiamos a él, pero, en el caso de las mujeres y los/as niños/as, jamás sin la mediación de los curas, los padres de familia, o alguna pequeña autoridad. Hemos trasladado este amor de "buen padre, severo pero justo" al resto de la creación. Y a veces, sin querer, es esta la forma de amor que evocamos cuando hablamos de cuidar. El amor que se acomoda a la explotación. 
"La justicia primero [dice Euguélionne ${ }^{8}$ ]. Entonces podrán hablar del amor universal y del amor a la Humanidad y de su futuro demográfico, y del amor del Hombre y del ser del Hombre y de su unidad, entonces podremos comenzar a tomarlos en serio" (Bersianik, 1976, p. 387).

Me pareció muy interesante cuando me enteré que ya han habido en Quebec sindicatos de trabajadores católicos que han querido, en un espíritu de amor cristiano, encontrar armonía con sus patrones. ${ }^{9}$ Lo que me interesa es que esta historia causa gracia hoy en día. Nos parece evidente que no resulte conveniente invitar al amor a la mesa de negociaciones, pero esto no siempre fue así. Y no lo es aún para el trabajo llamado femenino, el cuidado, la reproducción, y todas estas formas de trabajo esencial que las mujeres deberían realizar por vocación, por naturaleza, de forma gratuita (y de preferencia, en silencio). Hemos rechazado la separación entre amor y trabajo en estos casos. Las feministas marxistas exigen desacralizar todo esto y en cambio reconocer su gran valor a través del salario. Sin embargo, sabemos bien a qué tabú esta reivindicación se enfrenta: hemos tenido miedo de degradar el amor al contacto con el dinero.

E incluso si aceptáramos desacralizar y remunerar este tipo de trabajo, es decir, negociar los gestos de cuidado, el amor en sí mismo sigue siendo un tema de interés precisamente porque es incalculable. No quisiera dejar de lado esta

\footnotetext{
${ }^{8}$ N. de T. "L'Euguélionne”, publicada por Louky Bersianik en 1976, ha sido considerada la primera novela quebequense de inspiración feminista. En la novela, Euguélionne es una mujer de otro planeta que viene a ver como evoluciona el mundo, para encontrarse con que la mujer es tratada como un objeto.

${ }^{9}$ Tomo esta anécdota de La revolution des moeurs, un libro muy interesante de Jean-Marc Piotte (2016), que habla justamente de esta revolución incompleta.

Revista Zona Franca- Centro de estudios interdisciplinario sobre las mujeres (CEIM)- Maestría poder y sociedad desde la problemática de género (MG), Rosario, Argentina. ISSN, 2545-6504 http://zonafranca.unr.edu.ar/index.php/ZonaFranca| Numero 26 (2018). 
pregunta. Tener gestos "por amor", por compromiso, revela lo que para nosotros tiene mayor valor. La incapacidad de separar los sentimientos de la tarea a realizar es un buen indicador de su importancia. El cuidado, la educación, el respeto de la vida, todo esto se liga al amor, y puede ser que la transformación de la noción misma de amor sea lo que debemos integrar a nuestras reflexiones. El amor no está hecho más que de lazos; quizás aún lo vemos como algo demasiado razonable. Para los movimientos ecologistas, su lado rebelde también puede representar una fuerza preciosa e imprevisible. El amor, es aquello que, frente a la muerte, frente a la pregunta "Es normal ¿entiendes?", nos hace responder: "No, no lo entiendo".

En las sociedades occidentales, el amor ha vivido una revolución en el último siglo. Una revolución aplaudida por la contra-cultura y que se identifica con una generación que hoy día parece envejecida, pero que es un enorme logro feminista -el resultado de una gran batalla, ganada casa por casa, escuela por escuela, canción por canción. Gracias a las luchas íntimas y desconocidas de las mujeres de esta época, el ideal amoroso se ha vuelto en teoría igualitario. Lo hemos llamado "libre", y a menudo lo es, incluso si nos ata. Lo concebimos como una construcción de intercambios entre iguales. Y esta revolución no ha acabado.

Primero, encontramos todavía demasiados dinosaurios que fantasean con un amor romántico en el que la mujer está asegurada. Es necesario luchar sin cesar por justificar ante sus ojos que las novias no son una propiedad a defender. Al mismo tiempo, el precio que cada una ha pagado, y continúa pagando en la 
intimidad, por esta insubordinación a este amor asimétrico, es aún grande, tan grande que el feminismo da miedo, y es esperable que reciba su castigo. Luego, al interior de la familia hemos bloqueado esta revolución para los/as niños/as. Queremos tener derecho sobre ellos/as. Por todas partes, en todos los rincones de aquello que llamamos amor, quedan aires de posesión. Entonces, si es esto lo que queremos transformar, ¿por qué detenernos a estas alturas?

¿Y qué decir del amor por el mundo? Si nuestro amor es distinto al de los propietarios que tienen derecho sobre el mundo, si nuestro amor está hecho de respeto, de intercambio, de entrega mutua y de libertad, entonces todas nuestras interacciones con las otras especies, pero también con el medioambiente y aquello que no son nuestros recursos, debe cambiar. Los/as niños/as no nos pertenecen. El mundo tampoco. Pero esto no nos debería impedir nunca estar ligados/as a ellos por un contrato recíproco, una responsabilidad diferida.

Hoy en día, la tentación de rechazar esta revolución del amor es grande, en todo tipo de circuito, incluso los anticapitalistas. Ella es víctima de una ceguera clásica. Son asuntos de mujeres, frivolidades, contagian de aires afeminados a los grandes caballeros. ¿La igualdad? Una utopía para cobardes. ¿El fin de la violencia conyugal? Una preocupación egocéntrica.

Esta revolución inacabada tiene un importante trecho que atañe también a los hombres. Podemos pensar que la posesividad en el amor, y la razón de ser del patriarcado, en parte se explica por la imposibilidad de los hombres de determinar la paternidad, su alienación en la reproducción, su amor familiar inquieto, que de 
hecho ha justificado la guerra contra las mujeres y la obsesión por el control de sus cuerpos. Al mismo tiempo, es urgente poner en cuestión los grandes relatos que parten de intenciones y de principios positivos, pero que se fundan en esta angustia de castración. Estos discursos determinan la sexualidad como una forma de tomar el control, o valoran el hecho de entregar su vida por proteger a los demás en lugar de venir en su ayuda, como si fuera lo único que los hombres saben y pueden hacer.

Vivimos en un tiempo en que nos mentimos sobre la masculinidad y sobre la familia. Todos intentamos inventar una parentalidad basada en el cuidado y la familia, en la cooperación más que en la biología, pero esta negociación es privada, mientras que colectivamente continuamos haciendo como si una familia fuese un papá, una mamá y los/as hijos/as (y pertenencias y un auto). Colectivamente, continuamos minimizando la importancia de la revolución en curso. El amor no es un estado feliz y estable, sino una actividad reiterada, que da lugar a transformaciones, aprendizajes y reparaciones.

Será necesario que aceptemos que con una inversión de las prioridades viene la inversión de los poderes. Algunos hilos aún se nos escapan, el control del mundo se nos resbala entre los dedos mientras intentamos amarlo lo mejor posible. $\mathrm{Y}$ es necesario superar el miedo de perder para que el mundo pueda ganar. La supervivencia, la reproducción, es justamente el ámbito en el cual los gobiernos hacen los mayores recortes. Deshacemos todo lo que permit(ir)ía poner en común ese trabajo, esos recursos, esas necesidades, para dejar a los 
individuos como los únicos responsables de su suerte. $Y$ de este repliegue de las instituciones públicas se alimenta el care. La vida se patenta, se comercializa, se apuesta. La crisis de la reproducción es una privatización. Mientras que el cuidado del mundo y el amor del mundo que yo quisiera por sobre todo, pasan por una desposesión. Habitar la tierra es una experiencia que ocurre sin gloria ni ganancias. Me encantaría que aprendamos a tomar el poder que tenemos, que no tiene nada que ver con las posesiones, el poder del abono, la capacidad de participar del lento proceso de la continuidad. Ya sabemos cómo hacer. Primero tendríamos que dejar de desviarnos de lo que importa y dejar de creer que la solución a la crisis está en el movimiento que la ha provocado.

\section{Bibliografía}

bell hooks (2017 [1984]). De la marge au centre: théorie féministe, Cambourakis, Paris.

BERSIANIK, Louky (1976). L'Euguélionne, La Presse, Montreal.

KLEIN, Naomi (2015). Tout peut changer, Lux, Montreal.

O'BRIEN, Mary (1981). La dialectique de la reproduction, Éditions du remueménage, Montreal.

PIOTTE, Jean-Marc (2016). La revolution des moeurs, Québec-Amérique, Montreal.

TOUPIN, Louise (2014). Le salaire au travail ménager, Éditions du remueménage, Montreal. 